\title{
Cantharidin inhibits cell proliferation and induces apoptosis through G2/M phase cell cycle arrest in hepatocellular carcinoma stem cells
}

\author{
AI-PING LE ${ }^{1}$, LUN-LI ZHANG ${ }^{2}$, WEI LIU ${ }^{1}$ and YU-FEI SHI ${ }^{2}$ \\ Departments of ${ }^{1}$ Blood Transfusion and ${ }^{2}$ Infectious Diseases, First Affiliated Hospital \\ of Nanchang University, Nanchang, Jiangxi 330006, P.R. China
}

Received December 6, 2015; Accepted December 30, 2015

DOI: $10.3892 /$ or.2016.4684

\begin{abstract}
The present study was designed to investigate the effect of cantharidin on cell proliferation, ability of selfrenewal, cell cycle arrest and induction of apoptosis in HepG2 hepatocellular carcinoma stem cells (HCSCs). It was observed that cantharidin treatment exhibited dose- and time-dependent inhibitory effect on the viability of HCSCs. The inhibition of cell viability by cantharidin in $\mathrm{HepG} 2 \mathrm{CD} 133^{+}$and parental cells was significant at the concentration 5 and $15 \mu \mathrm{M}$, respectively after $48 \mathrm{~h}$. Cantharidin treatment inhibited the self-renewal ability of the HCSCs and the expression of $\beta$-catenin and cyclin D1. Flow cytometry revealed that cantharidin treatment at $5 \mu \mathrm{M}$ concentration significantly increased the cell population in $\mathrm{G} 2 / \mathrm{M}$ phase and decreased the population in the $\mathrm{G} 1$ phase. Cantharidin treatment in the HCSCs for $48 \mathrm{~h}$ increased expression of histone $\mathrm{H} 2 \mathrm{AX}$, Myt1, cyclin A2, cyclin B1, p53 and cdc2 (Tyr15) phosphorylation significantly compared to the parental cells. Exposure of the HCSCs to cantharidin for $48 \mathrm{~h}$ at a concentration of $5 \mu \mathrm{M}$ caused a significant increase in the proportion of apoptotic cells. Therefore, cantharidin is a promising agent for the hepatocellular carcinoma treatment.
\end{abstract}

\section{Introduction}

Hepatocellular carcinoma (HCC) is one of the major causes of cancer deaths throughout the globe and every year around 600,000 new cases are detected $(1,2)$. The rate of prognosis in HCC patients is very poor and depends on the stage of diagnosis. The commonly used treatment strategies for HCC at present include, chemotherapy, radiation therapy and surgery, however, none of the strategies are sufficiently efficient (3).

Correspondence to: Dr Ai-Ping Le, Department of Blood Transfusion, First Affiliated Hospital of Nanchang University, 17 Yongwaizheng Street, Nanchang, Jiangxi 330006, P.R. China E-mail: leaiping@hotmail.com

Key words: apoptosis, cantharidin, self-renewal, inhibition, cell cycle
Metastasis of HCC to other organs including lungs, lymph nodes, kidneys and brain is commonly observed in the patients with liver cancer (4). Thus, the discovery of new molecules for the treatment of hepatocellular carcinoma is required. A small population of cancer cells bestowed with the ability to initiate, promote and sustain tumor growth is known as cancer stem cells (CSCs) $(5,6)$. These cells are capable of undergoing selfrenewal and proliferation at an enormous rate (7). CSCs are resistant to radiotherapy as well as chemotherapy and facilitate the metastasis of cancer cells to various other organs. Thus, it is believed that targeting the CSCs can be a promising strategy for the treatment of cancer.

Natural products isolated from plant and animal sources have been the source of drugs for various diseases (8). Cantharidin is obtained by the phytochemical analysis of Blister Beetles and belongs to the class of terpenoids (8). Cantharidin has a long traditional medicinal importance in Chinese system of medicine (9). The mechanism of action of cantharidin has been found to involve arrest of cell cycle and induction of apoptosis in the cancer cells $(10,11)$. Cantharidin treatment exhibits inhibitory effect on various types of cancer cells including, colon, liver, breast, bladder oral buccal and leukemia (11-15). Treatment of T24 cells with cantharidin induces expression of COX2, PGE2 and causes cell cycle arrest in G2/M phase (13). However, the effect of cantharidin on cell proliferation and self-renewal, cell cycle arrest and induction of apoptosis in HCSCs have not been reported. Therefore, the effect of cantharidin on the hepatocellular carcinoma stem cells was investigated. It was observed that cantharidin treatment inhibited cell viability and self-renewal capacity, arrested the cell cycle and induced apoptosis in HepG2 CD133+ HCSCs.

\section{Materials and methods}

Chemical and reagents. Cantharidin and dimethyl sulphoxide (DMSO) were purchased from Sigma-Chemical Co. (St. Louis, MO, USA). Trypsin, MTT reagent and lithium chloride were purchased from Gibco-BRL (Grand Island, NY, USA). The antibodies for human $\beta$-catenin, cyclin D1 and $\beta$-actin were obtained from the Health Science Research Resources Bank (Osaka, Japan). 
Cell lines and culture. The HepG2 hepatocellular carcinoma cell line was purchased from the American Type Culture Collection (ATCC; Manassas, VA, USA). The cells were maintained in RPMI-1640 medium (RPMI:ECM=4:1) supplemented with $10 \%$ fetal bovine serum in a humidified atmosphere of $5 \% \mathrm{CO}_{2}$ and $95 \%$ air at $37^{\circ} \mathrm{C}$.

Cell separation and culture of spheres. HepG2 hepatocellular carcinoma cells were sorted using magnetic activated cell sorting (MACS) separation column (BD Biosciences, Mountain View, CA, USA) based on the presence of surface marker, CD133+. Briefly, the cells after phosphate-buffered saline (PBS) washing were treated with $0.5 \%$ bovine serum albumin (BSA). To the $200 \mu \mathrm{l}$ of anti-CD133 antibody were added $200 \mu 1$ of CD133-conjugated MicroBeads, $2 \times 10^{7}$ cells and the sample. After incubation for $1 \mathrm{~h}$, the cells were rinsed in PBS and then $\mathrm{CD}_{133^{+}}$and $\mathrm{CD}^{-} 33^{-}$cells were separated. The $\mathrm{CD}_{133^{+}}$and parental cells were rinsed twice in PBS followed by incubation in serum-free RPMI-1640 containing antibiotics, penicillin and streptomycin. The cells at a density of $2 \times 10^{5}$ cells $/ \mathrm{ml}$ were distributed onto 6 -well ultralow attachment plates (BD Biosciences) in stem cell media. Following incubation for 5 days the cultures were passaged to determine the number of colonies with more than 50 cells per colony using a microscope (IX71; Olympus, Tokyo, Japan). All the calculations were performed in triplicate.

Analysis of colony formation. The effect of cantharidin treatment on formation of colonies in HepG2 $\mathrm{CD} 133^{+}$cells was also determined. Briefly, the cells at a density of $2 \times 10^{5}$ cells $/ \mathrm{ml}$ were seeded onto 96 -well plates. The cells were incubated with various concentrations of cantharidin dissolved in DMSO or with DMSO alone as negative control. Following incubation for a period of 5 days, the ability of the cells to form colonies was determined by counting the number of colonies using an Olympus CX22 microscope (Olympus).

The sphere forming ability of the cells was analyzed after $2.5 \times 10^{5}$ cells $/ \mathrm{ml}$ were seeded onto 6 -well ultralow attachment plates. In another experiment, $1 \times 10^{5}$ cells $/ \mathrm{ml}$ were distributed on to the 6-well ultralow attachment plates and then treated with different doses of cantharidin. HepG $2 \mathrm{CD} 133^{+}$single cell suspensions were exposed to cantharidin $(5 \mu \mathrm{M})$, lithium chloride $(2 \mu \mathrm{M})$, casticin- $\mathrm{LiCl}(5$ or $5 \mu \mathrm{M})$ or control to DMSO, respectively. After $24 \mathrm{~h}$, the effect of cantharidin on the ability of cells to form a carcinoma mass was analyzed.

In vivo tumorigenicity assay. Twenty pathogen-free male $\mathrm{Balb} / \mathrm{c}$ nu mice (56 weeks of age) were purchased from the Animal Institute of the Chinese Academy of Medical Science. The animal studies were performed in accordance with the standard protocols approved by the Ethics Committee of Hunan National University and the Committee of Experimental Animal Feeding and Management (Changsha, China). The study was approved by the Ethics Committee of Hunan National University and the Committee of Experimental Animal Feeding and Management (Changsha, China) under the reference number 007/2013-HNU. The mice were randomly divided into five groups ( $n=4$ per group) and maintained under standard conditions, according to typical protocols. The cells were suspended in a serum-free DMEM/Matrigel
(BD Biosciences, Franklin Lakes, NJ, USA) mixture (1:1 volume). The mice were inoculated with different quantities of CD133 ${ }^{+}$SFCs $\left(5 \times 10^{2}, 1 \times 10^{3}, 5 \times 10^{3}, 1 \times 10^{4}\right.$ and $5 \times 10^{4}$ cells $)$ in one flank, and unsorted MHCC97 cells $\left(5 \times 10^{4}, 1 \times 10^{5}, 2 \times 10^{5}, 5 \times 10^{5}\right.$ and $1 \times 10^{6}$ cells) in the other. Tumorigenicity experiments were terminated two months after cell inoculation. Tumor size was measured using a caliper and the volume was calculated as follows: $\mathrm{V}\left(\mathrm{mm}^{3}\right)=\mathrm{L} \times \mathrm{W} 2 \times 0.5$, where $\mathrm{L}$ denotes length and $\mathrm{W}$ the width. The harvested tumors were photographed and weighed immediately. Specimens from tumor tissue samples were fixed in $10 \%$ neutral buffered formalin, processed in paraffin blocks and sectioned. The sections were stained with hematoxylin and eosin (H\&E) and examined under an inverted microscope (IX71; Olympus).

MTT assay. On to the 96-well tissue culture plates $2.5 \times 10^{5}$ $\mathrm{CD}_{133}{ }^{+}$or parental HepG 2 cells were dispersed and cultured in RPMI-1640 supplemented with $10 \%$ fetal bovine serum along with $2 \mathrm{mM}$ L-glutamine. The cells after attachment for $12 \mathrm{~h}$ were treated with various concentrations of cantharidin for $36 \mathrm{~h}$. To each well of the plate, $150 \mu 1$ 3-(4,5-dimethylthiazol2-yl)-2,5-diphenyltetrazolium bromide (MTT) and incubated for $4 \mathrm{~h}$. DMSO $(150 \mu \mathrm{l})$ was added to each well of the plate to dissolve the formed formazan crystals. A microplate reader (SpectraMax Plus; Molecular Devices) was used to measure absorbance for each well at $465 \mathrm{~nm}$ three times independently. All the experiments were performed three times.

Analysis is apoptosis. CD133+ or parental HepG2 cells were seeded at a density of $3 \times 10^{5}$ cells into the $10-\mathrm{cm}$ culture dishes to attain confluence overnight. The cells were exposed to cantharidin in DMSO or DMSO alone as the control for $48 \mathrm{~h}$. FACSCalibur flow cytometer (BD Biosciences, San Jose, CA, USA) and the fluorescein isothiocyanate (FITC) Annexin V apoptosis detection kit (BD Biosciences, San Diego, CA, USA) were used to analyze the percentage of apoptotic cells according to the manufacturer's instruction.

Cell cycle analysis. CD133+ or parental HepG2 cells were seeded at a density of $3 \times 10^{6}$ cells into the tissue culture flasks (T75 flask; Nunc A/S). The flasks were supplemented with RPMI-1640 medium containing 2\% FBS and incubated for $24 \mathrm{~h}$ with various doses of cantharidin. Following incubation, the cells were rinsed in PBS buffer and fixed in $70 \%$ ethanol overnight at $40^{\circ} \mathrm{C}$. Cell contents were subjected to centrifugation at $15000 \mathrm{x} \mathrm{g}$ for half an hour and then treated with $200 \mu \mathrm{l}$ PBS supplemented with $1 \mathrm{mM}$ RNase A (Calbiochem, San Diego, CA, USA) for $40 \mathrm{~min}$. Propidium iodide (Sigma-Aldrich) at the concentration of $50 \mu \mathrm{g} / \mathrm{ml}$ was added to the cell cultures and incubation was continued for half an hour. DNA content of the cells was examined using FACSVantage SE flow cytometry system and CellQuest program (BD Biosciences).

Western blot analysis. The cells deprived of serum were treated with cantharidin or only DMSO as control in 6-well plates for $24 \mathrm{~h}$. Following incubation, the cells were washed with PBS and then treated with lysis buffer $(50 \mu \mathrm{M}$ Tris- $\mathrm{HCl}$ $\mathrm{pH} 7.4,10 \%$ glycerol, $137 \mu \mathrm{M} \mathrm{NaCl}, 1 \mu \mathrm{M}$ PMSF, $100 \mu \mathrm{M}$ sodium vanadate, $10 \mathrm{mg} / \mathrm{ml}$ leupeptin, $10 \mathrm{mg} / \mathrm{ml}$ aprotinin, 

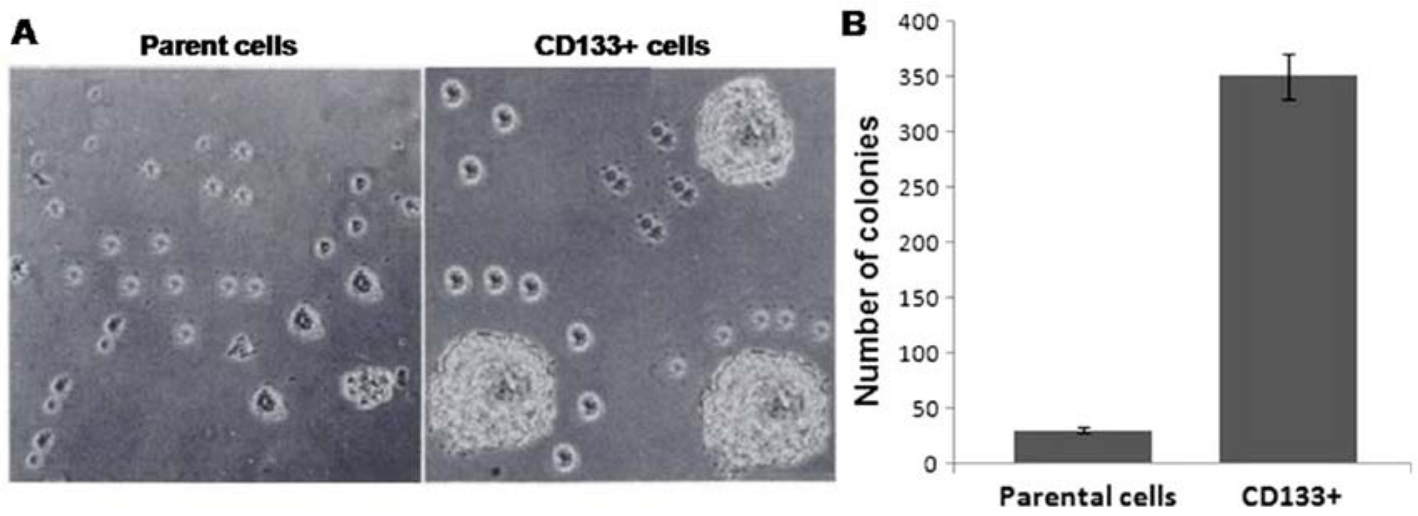

Figure 1. Separated CD133 ${ }^{+}$HCSCs and parental cells from the HepG2 cell line formed spheroids. (A and B) CD133 ${ }^{+}$cells obtained from the HepG2 cells and PCs formed carcinoma mass on culture in stem cell-conditioned medium. The data presented are the mean \pm standard deviation $(n=3)$.
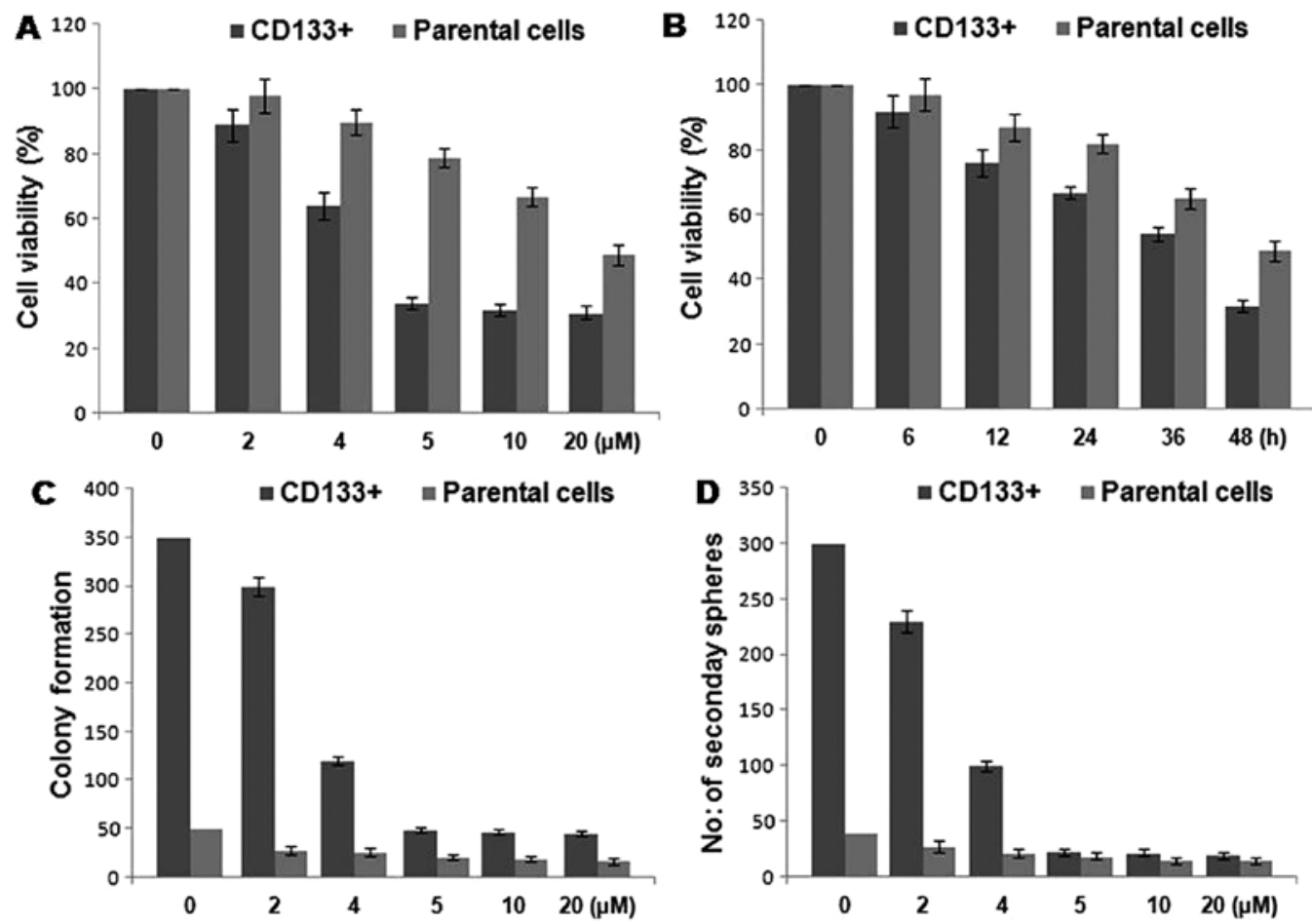

Figure 2. Cantharidin preferentially inhibits proliferation and self-renewal of HCSCs derived from the HepG2 cell line. (A and B) Cantharidin inhibited the viability of $\mathrm{CD}_{133}{ }^{+} \mathrm{HCSC}$ preferentially in concentration and time-dependent manner. (C) HCSCs were incubated with various concentrations of cantharidin $(0-20 \mu \mathrm{M})$ for five days. (D) cantharidin treatment reduced the number of secondary tumorspheres formed from primary tumorspheres compared with the control. The data expressed are the mean \pm standard deviation $(n=3)$.

$1 \% \mathrm{NP}-40$ and $5 \mu \mathrm{M}$ cocktail). Concentration of proteins in the cell lysates was determined by bicinchoninic acid assay (BCA) method. The proteins were separated on to $10 \%$ polyacrylamide gel and then transferred to a PVDF membrane. The membrane was blocked overnight using 5\% non-fat dry milk followed by TBST washing. The membrane was then incubated for $12 \mathrm{~h}$ with primary antibodies for $\beta$-catenin or cyclin D1, washed with TBST followed by incubation with secondary antibodies for $1 \mathrm{~h}$. The X-ray autoradiography was performed and the gray scale images were analysed.

Statistical analysis. The data expressed are the mean \pm SD. The differences between the groups were analyzed using Student's t-test and SPSS software, version 15.0 (SPSS, Inc.,
Chicago, IL, USA). The differences at $\mathrm{P}<0.05$ were considered statistically significant.

\section{Results}

Separation of hepatocellular carcinoma stem cells from HepG2 cell line. The $\mathrm{CD}_{133^{+}}$cells were separated from HepG2 cell cultures by examination using FCM and then cultured to obtain stem cell rich cultures, and at 5 days, the spheroids formed by $\mathrm{CD} 133^{+}$and parental cells were collected. It was observed that compared to $\mathrm{CD} 133^{+}$cells, the parental cells formed larger sized and more number of tumorspheres (Fig. 1A). Analysis of the capacity of selfrenewal revealed that $\mathrm{CD} 133^{+}$cells formed spheroidal mass of undifferentiated 


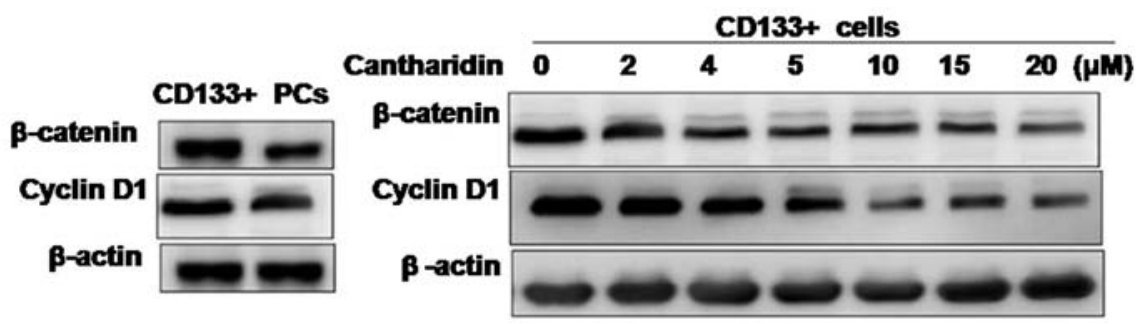

Figure 3. Inhibition of $\beta$-catenin and cyclin D1 expression in HCSCs obtained from HepG2 cell line by treatment with cantharidin. The expression of $\beta$-catenin and cyclin D1 was higher in CD133 ${ }^{+}$HCSCs compared to the PCs. Cantharidin inhibited the expression of $\beta$-catenin and cyclin D1 in CD133 ${ }^{+} \mathrm{HCSCs}$ in concentration-dependent manner. PC, parental cell.

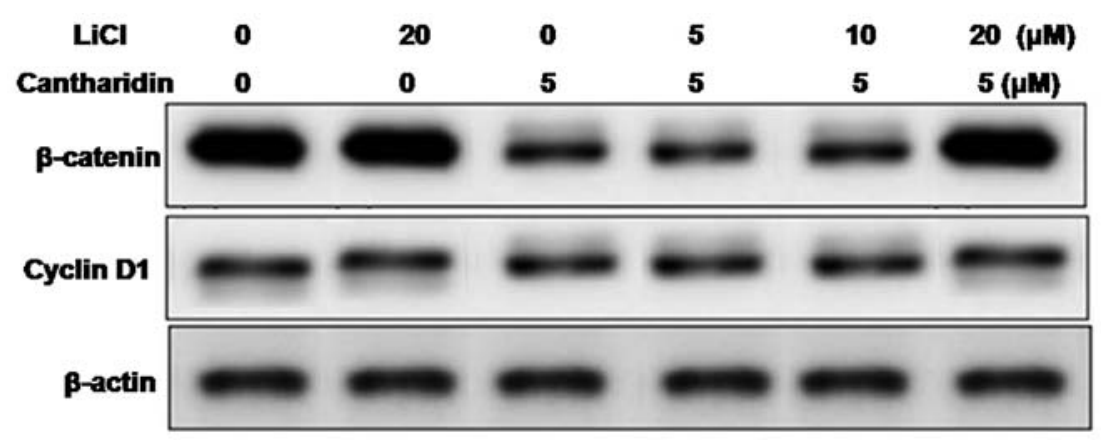

Figure 4. Treatment of lithium chloride pretreated HCSCs WITH cantharidin prevented the inhibition of $\beta$-catenin and cyclin D1. LiCL, lithium chloride.

\section{Cantharidin}
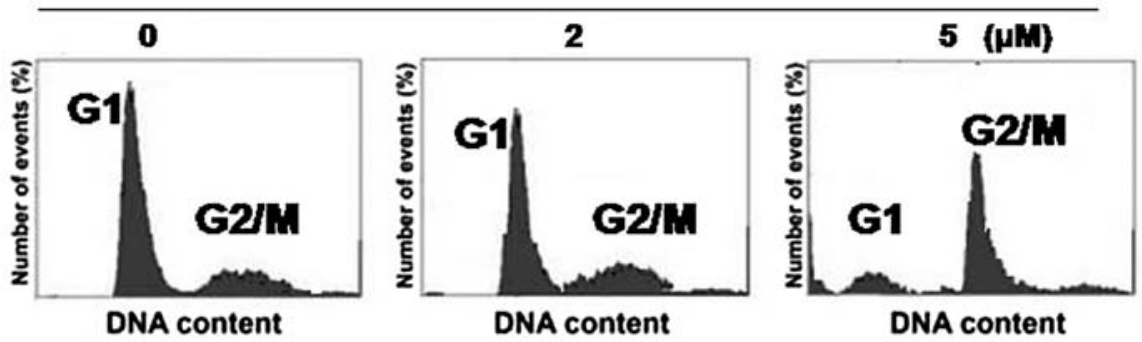

Figure 5. Cantharidin treatment caused cell cycle arrest in HCSCs in G2/M phase. The cells after incubation with cantharidin for $24 \mathrm{~h}$ were fixed and then stained with propidium iodide to analyze the DNA content.

$\mathrm{CD}_{133^{+}}$cells within 5 days (Fig. 1B). Thus, $\mathrm{CD}_{133^{+} \text {cells }}$ possess the capacity of self-renewal.

Inhibition of proliferation and selfrenewal of HCSCs from the HepG2 cell line by cantharidin. The cells were exposed to various concentrations of cantharidin from 0 to $20 \mu \mathrm{M}$ for various time periods. The results revealed a concentrationdependent inhibition of cell viability of $\mathrm{CD}_{133^{+}} \mathrm{HCSCs}$ by cantharidin after $48-\mathrm{h}$ treatment. The reduction in cell viability of $\mathrm{CD}_{133}{ }^{+} \mathrm{HCSC}$ was significant at $5 \mu \mathrm{M}$ concentration of cantharidin. However, in parental cells the inhibition in viability was significant at $20 \mu \mathrm{M}$ concentration after $48 \mathrm{~h}$ (Fig. 2A and B). Cantharidin treatment at a concentration of $5 \mu \mathrm{M}$ significantly inhibited the tendency of colony formation in HCSCs after $48 \mathrm{~h}$. Compared to the primary tumorspheres of HCSCs of untreated group, the number of primary as well as secondary tumorspheres in the cantharidin treated cultures were significantly reduced (Fig. 2C and D).
Inhibition of selfrenewal in HCSCs by cantharidin involves alteration in $\beta$-catenin expression. Effect of cantharidin treatment on the expression of $\beta$-catenin and cyclin D1 in $\mathrm{CD}_{133}{ }^{+} \mathrm{HCSC}$ and parental cells was analyzed by western blot analysis. Results showed a significantly higher expression of $\beta$-catenin and cyclin D1 in the CD133 ${ }^{+} \mathrm{HCSC}$ compared to the parental cells. However, cantharidin treatment induced a concentration-dependent inhibition of $\beta$-catenin and cyclin D1 expression. The reduction in expression of $\beta$-catenin and cyclin D1 was significant at the concentration of $5 \mu \mathrm{M}$ of cantharidin after $48 \mathrm{~h}$ in HCSCs (Fig. 3).

Treatment of the HCSCs with lithium chloride, a factor known for activation of $\mathrm{Wnt} / \beta$-catenin pathway led to the enhancement in expression of $\beta$-catenin and cyclin D1. When the lithium chloride pretreated HCSCs were exposed to cantharidin the inhibition in expression of $\beta$-catenin and cyclin D1 caused by cantharidin was suppressed (Fig. 4). Since $\beta$-catenin pathway plays an important role in the self-renewal 


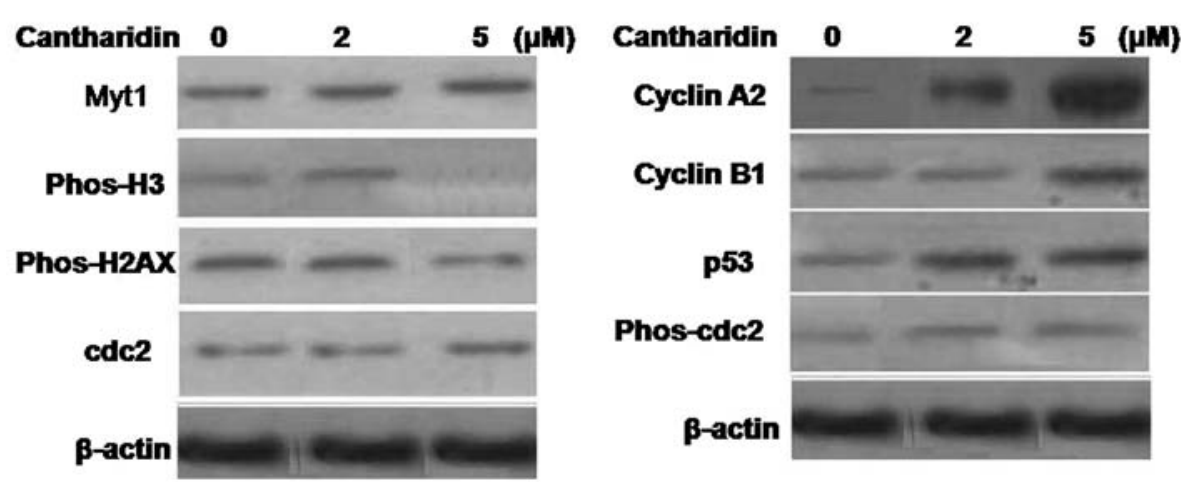

Figure 6. Effect of cantharidin on the expression of cell cycle regulatory proteins in HCSCs and parental cells. Treatment of HCSCs and parental cells with cantharidin was followed by western blot analysis to determine the alterations in the protein expression.

A

Cantharidin

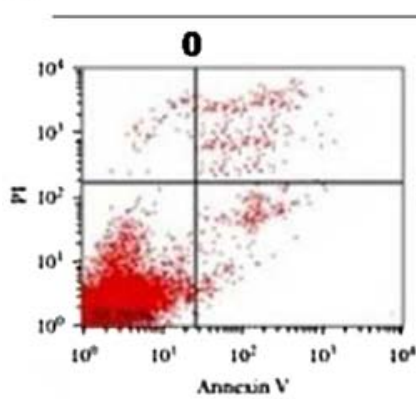

B

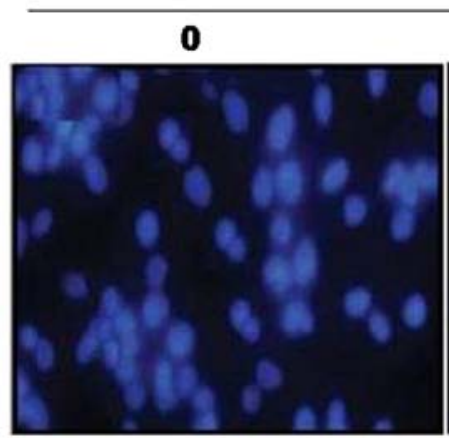

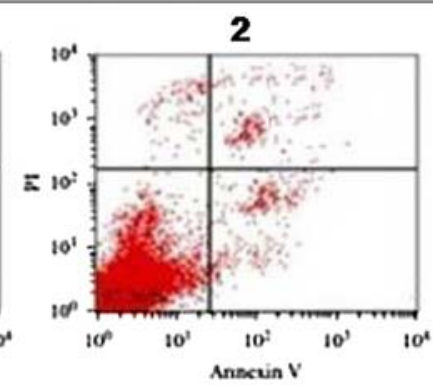

Cantharidin
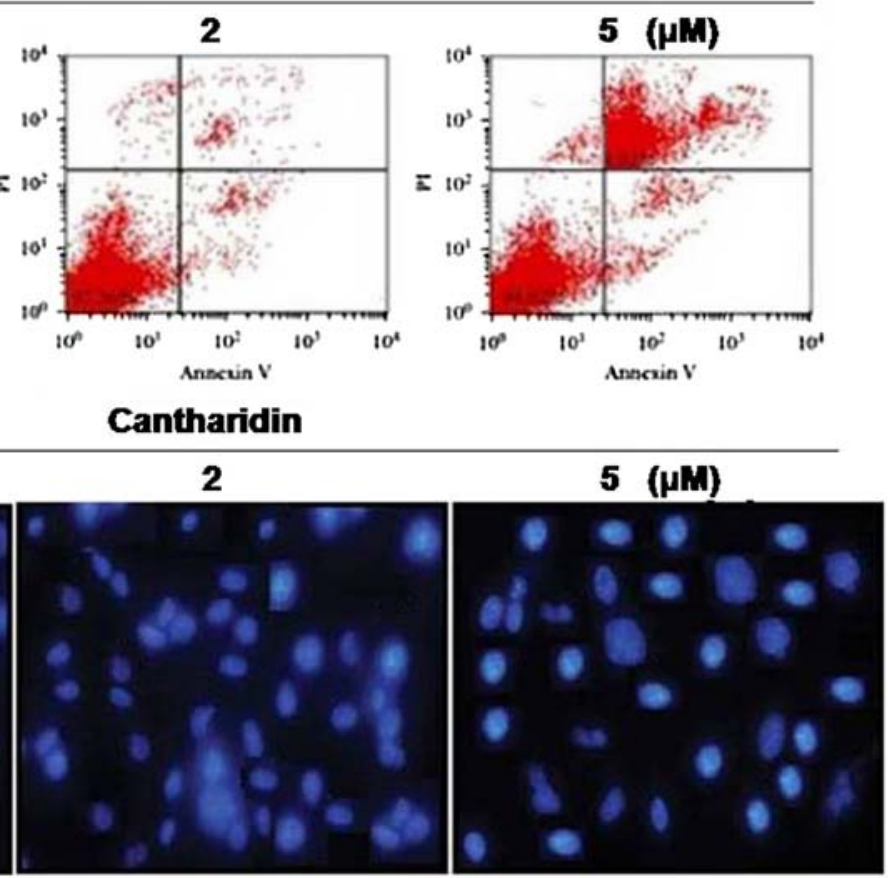

Figure 7. Cantharidin treatment induced apoptosis in HCSCs and parental cells. (A) The cells after treatment with cantharidin for 24 and $48 \mathrm{~h}$ were subjected Annexin VFITC and PI labeling to determine the induction of apoptosis. (B) The cells after cantharidin treatment for 24 and $48 \mathrm{~h}$ were analyzed by immunofluorescence.

of cancer stem cells, cantharidin treatment in HCSCs inhibits self-renewal by inhibiting the expression of $\beta$-catenin and cyclin D1.

Cantharidin treatment arrests cell cycle in G2/M phase in the HCSCs. Flow cytometry was used to analyze the effect of cantharidin on cell cycle in the HCSCs. It was observed that cantharidin treatment at $5 \mu \mathrm{M}$ concentration significantly enhanced the cell population in $\mathrm{G} 2 / \mathrm{M}$ phase and decreased the population in the G1 phase. The population of $\mathrm{CD} 133^{+} \mathrm{HCSCs}$ in the $\mathrm{G} 2 / \mathrm{M}$ phase increased from $19.5 \pm 1.8$ to $73.4 \pm 4.2 \%$ with the increase in treatment time from 24 to $48 \mathrm{~h}$. In G1 phase the population of cells decreased from $17 \pm 2.0$ to $9.6 \pm 1.8 \%$ with the increase in treatment time from 24 to $48 \mathrm{~h}$. However, in parental cells the proportion of cells in $\mathrm{G} 2 / \mathrm{M}$ phase were 7.5 \pm 1.2 and $11.2 \pm 2.1 \%$, respectively after 24 and 48 h (Fig. 5).
Alteration in cell cycle regulatory proteins by cantharidin treatment in the HCSCs. Cantharidin treatment in the HCSCs for $48 \mathrm{~h}$ induced a significant increase in histone H2AX expression compared to the parental cells. It also promoted the Myt1 protein expression and cdc2 (Tyr15) phosphorylation in HCSCs (Fig. 6). Analysis of cyclin A2, cyclin B1 and p53 revealed a significant increase in the expression of all the three proteins in the cantharidin treated HCSCs. However, the histone $\mathrm{H} 3$ expression was inhibited significantly in HCSCs on treatment with cantharidin for $48 \mathrm{~h}$.

Induction of apoptosis in HCSCs by cantharidin treatment. Exposure of the HCSCs to cantharidin for $48 \mathrm{~h}$ at a concentration of $5 \mu \mathrm{M}$ caused a significant increase in the proportion of apoptotic cells. Annexin V/FITC staining showed that cantharidin treatment significantly increased 
the Annexin V/FITCstained HCSCs cells compared to the untreated cells (Fig. 7A). HCSCs cells treated with cantharidin for $48 \mathrm{~h}$ showed significant morphological alterations by immunofluorescence (Fig. 7B).

\section{Discussion}

Carcinoma stem cells (CSCs) play a vital role in the progression of cancer and its resistance to chemotherapeutic agents. Therefore, inhibition of CSC proliferation by arresting cell cycle and induction of apoptosis is of promising importance for the treatment of cancer (16). It is reported that CSC proliferation can be inhibited by targeting a number of factors including hedgehog, Wnt/ß-catenin, Notch and EGFR pathways $(17,18)$. The present study demonstrates the effect of cantharidin on inhibition of cell proliferation, self-renewal, cell cycle arrest and induction of apoptosis in $\mathrm{CD} 133^{+}$hepatocellular carcinoma cell line, derived from HepG2 cell line. It was observed that cantharidin treatment inhibited cell viability and tendency of self-renewal, arrested cell cycle in $\mathrm{G} 2 / \mathrm{M}$ phase and induced apoptosis in $\mathrm{CD} 133^{+}$HCSCs. CSCs are present in various types of cancers and are identified on the basis of presence of CD133, surface marker (19). In the present study, CD133+ HCSCs were separated from HepG2 cell lines and cultured in media conditioned for stem cell to form tumorspheres. It was observed that $\mathrm{CD} 133^{+} \mathrm{HCSC}$ formed larger sized and greater number of tumorspheres compared to the parent cells. Exposure of the HCSCs to cantharidin significantly inhibited the cell proliferation and tendency of self-renewal after $48 \mathrm{~h}$ of treatment compared to the parental cells. Cantharidin treatment also led to inhibition of the tendency to form spheres in HCSCs.

Wnt $/ \beta$-catenin signaling pathway plays an important role in the self-renewal of the cancer stem cells and hence progression and invasion of carcinoma (20). Therefore, the effect of cantharidin on the $\beta$-catenin and cyclin D1 expression was also investigated. It was observed that cantharidin treatment significantly inhibited the $\beta$-catenin and cyclin D1 expression in $\mathrm{CD}_{133^{+}}$HCSCs compared to the parental cells. However, lithium chloride, a factor known for activation of Wnt/ $\beta$-catenin pathway exposure to cantharidin pretreated cells prevented the cantharidin-induced inhibition of $\beta$-catenin and cyclin D1 expression. These findings suggest that inhibition of self-renewal in CD133+ ${ }^{+} \mathrm{HCSCs}$ by cantharidin treatment is associated with $\beta$-catenin and cyclin D1 expression.

Progression of cell cycle is regulated by various factors including, cyclins and cyclin-dependent kinases and activated cdc2-linked cyclin A and cyclin B regulate the progression of G2/M phase. Activation of cdc2 Tyr15 and Thr14 by Myt1 kinases results in inactivation of the cdc2/cyclin B complex (21-23). In the present study cantharidin treatment significantly increased the expression of Myt1 protein in $\mathrm{CD}_{133^{+}}$ HCSCs. The phospho-cdc2 (Tyr15) and cyclin A2 protein expression was also promoted in $\mathrm{CD}_{133^{+}} \mathrm{HCSC}$ compared to the parental cells. The phosphorylation of histone $\mathrm{H} 2 \mathrm{AX}$ proteins was increased and the cell cycle was arrested in the $\mathrm{G} 2 / \mathrm{M}$ phase. The process of apoptosis involving the removal of damaged cell is inhibited in the carcinoma cells (24). In the present study cantharidin treatment induced apoptosis in
CD $133^{+}$HCSCs significantly compared to the parental cells after $48 \mathrm{~h}$.

In conclusion, cantharidin treatment inhibits proliferation and self-renewal, arrests cell cycle in $\mathrm{G} 2 / \mathrm{M}$ phase and induces apoptosis in $\mathrm{CD} 133^{+} \mathrm{HCSC}$ derived from HepG2 cell line. Therefore, cantharidin is a potent agent for the inhibition of hepatocellular carcinoma.

\section{Acknowledgements}

The study was supported by the Jiangxi Major Technology Project (no. 20144BBG70001).

\section{References}

1. Ma S, Chan KW and Guan XY: In search of liver cancer stem cells. Stem Cell Rev 4: 179-192, 2008.

2. Tomuleasa C, Soritau O, Rus-Ciuca D, Pop T, Todea D, Mosteanu O, Pintea B, Foris V, Susman S, Kacsó G, et al: Isolation and characterization of hepatic cancer cells with stem-like properties from hepatocellular carcinoma. J Gastrointestin Liver Dis 19: 61-67, 2010.

3. Ricci-Vitiani L, Lombardi DG, Pilozzi E, Biffoni M, Todaro M, Peschle C and De Maria R: Identification and expansion of human colon-cancer-initiating cells. Nature 445: 111115, 2007.

4. Lee TK, Castilho A, Ma S and Ng IO: Liver cancer stem cells: Implications for a new therapeutic target. Liver Int 29: 955-965, 2009.

5. Mackillop WJ, Ciampi A, Till JE and Buick RN: A stem cell model of human tumor growth: Implications for tumor cell clonogenic assays. J Natl Cancer Inst 70: 9-16, 1983.

6. Gupta PB, Chaffer CL and Weinberg RA: Cancer stem cells: Mirage or reality? Nat Med 15: 1010-1012, 2009.

7. Chiba T, Kita K, Zheng YW, Yokosuka O, Saisho H, Iwama A, Nakauchi $\mathrm{H}$ and Taniguchi $\mathrm{H}$ : Side population purified from hepatocellular carcinoma cells harbors cancer stem cell-like properties. Hepatology 44: 240-251, 2006.

8. Curry SC, Carlton MW and Raschke RA: Prevention of fetal and maternal cyanide toxicity from nitroprusside with coinfusion of sodium thiosulfate in gravid ewes. Anesth Analg 84: 1121-1126, 1997.

9. Honkanen RE: Cantharidin, another natural toxin that inhibits the activity of serine/threonine protein phosphatases types 1 and 2A. FEBS Lett 330: 283-286, 1993.

10. Clarke PR, Hoffmann I, Draetta G and Karsenti E: Dephosphorylation of cde25-C by a type-2A protein phosphatase: Specific regulation during the cell cycle in Xenopus egg extracts. Mol Biol Cell 4: 397-411, 1993.

11. Chen YN, Chen JC, Yin SC, Wang GS, Tsauer W, Hsu SF and Hsu SL: Effector mechanisms of norcantharidin-induced mitotic arrest and apoptosis in human hepatoma cells. Int J Cancer 100: $158-165,2002$.

12. Kok SH, Cheng SJ, Hong CY, Lee JJ, Lin SK, Kuo YS, Chiang CP and Kuo MY: Norcantharidin-induced apoptosis in oral cancer cells is associated with an increase of proapoptotic to antiapoptotic protein ratio. Cancer Lett 217: 43-52, 2005.

13. Huan SK, Lee HH, Liu DZ, Wu CC and Wang CC: Cantharidininduced cytotoxicity and cyclooxygenase 2 expression in human bladder carcinoma cell line. Toxicology 223: 136-143, 2006.

14. Williams LA, Möller W, Merisor E, Kraus W and Rösner H: In vitro anti-proliferation/cytotoxic activity of cantharidin (Spanish Fly) and related derivatives. West Indian Med J 52: 10-13, 2003.

15. Yi SN, Wass J, Vincent $\mathrm{P}$ and Iland $\mathrm{H}$ : Inhibitory effect of norcantharidin on K562 human myeloid leukemia cells in vitro. Leuk Res 15: 883-886, 1991.

16. Naujokat $\mathrm{C}$ and Steinhart R: Salinomycin as a drug for targeting human cancer stem cells. J Biomed Biotechnol 2012: 950658, 2012.

17. Wang Z, Li Y, Ahmad A, Azmi AS, Kong D, Banerjee S and Sarkar FH: Targeting miRNAs involved in cancer stem cell and EMT regulation: An emerging concept in overcoming drug resistance. Drug Resist Updat 13: 109-118, 2010. 
18. Liu J, Kopecková P, Bühler P, Wolf $\mathrm{P}$, Pan H, Bauer H, Elsässer-Beile U and Kopeček J: Biorecognition and subcellular trafficking of HPMA copolymeranti PSMA antibody conjugates by prostate cancer cells. Mol Pharm 6: 959970, 2009.

19. Mizrak D, Brittan M and Alison M: CD133: Molecule of the moment. J Pathol 214: 3-9, 2008

20. Li L, Ying J, Li H, Zhang Y, Shu X, Fan Y, Tan J, Cao Y, Tsao SW, Srivastava G, et al: The human cadherin 11 is a proapoptotic tumor suppressor modulating cell stemness through $\mathrm{Wnt} /$ betacatenin signaling and silenced in common carcinomas. Oncogene 31: 39013912, 2012.

21. Booher RN, Holman PS and Fattaey A: Human Myt1 is a cell cycle-regulated kinase that inhibits Cdc2 but not Cdk2 activity. J Biol Chem 272: 22300-22306, 1997.
22. Liu F, Stanton JJ, Wu Z and PiwnicaWorms H: The human Myt1 kinase preferentially phosphorylates Cdc2 on threonine 14 and localizes to the endoplasmic reticulum and Golgi complex. Mol Cell Biol 17: 571583, 1997.

23. Parker LL and Piwnica-Worms H: Inactivation of the p34cdc2cyclin B complex by the human WEE1 tyrosine kinase. Science 257: 19551957, 1992.

24. Raff MC, Barres BA, Burne JF, Coles HS, Ishizaki Y and Jacobson MD: Programmed cell death and the control of cell survival: Lessons from the nervous system. Science 257: 1955-1957, 1992. 